\title{
Mining the Gap: Assessing Leadership Needs to Improve 21st Century Plant Pathology
}

\author{
J. Beckerman \\ Department of Botany and Plant Pathology, Purdue University, West Lafayette, IN 47907 \\ W. Schneider \\ Foreign Disease-Weed Science Research Unit, USDA-Agricultural Research Service, \\ Fort Detrick, MD 21702
}

Plant pathology is a multidisciplinary branch of the plant sciences, drawing on botany, mycology, microbiology, soil science, statistics, and many other fields in an effort to improve plant health and crop/ ecosystem sustainability. For plant pathologists to continue to contribute effectively in addressing these issues, their educational and professional experience must prepare them to do so. The training and development of a plant pathologist is designed to impart a combination of scientific knowledge and technical expertise, the completion of which often results in a graduate degree. This traditional process of graduate education is organized around a research question and provides the necessary credentials, a "passport," for a career in the research community (Austin 2002). Currently, training often focuses on technical expertise and scientific knowledge, with an understanding that the science is the primary concern, and social and interpersonal skills, although nice, are less necessary for long-term scientific success (Bancino and Zevalkink 2007).

This format of graduate education does not prepare students for the realities of the workforce and fails to recognize that more than half of new graduates with $\mathrm{Ph}$.D. degrees now find work in nonacademic settings (Austin 2002; Cyranoski et al. 2011; Gadoury et al. 2009). Today, graduate students and postdoctoral scientists develop increasingly diverse career paths, with many scientists pursuing research careers outside of academia; others are leaving research altogether. Data suggest that this trend will continue to grow (Benderly 2010; NRC 2010). The current pattern of training graduate students does not address the growing ranks of employers who describe new Ph.D.'s as “often too specialized" for the range of tasks that they will confront and who are unable to adapt to the changing demands of work, governmental unit, or even funding agencies (The Economist 2010). This suggests that an even greater majority of professionals who enter industry or government will not have the preparation necessary for scientific success. Although we recognize that current and future job opportunities will continue to favor students with the right diversity and breadth of scientific and technical expertise, the training and development of "soft skills" continues to lag behind (Bancino and Zevalkink 2007).

Soft skills (also called human capital skills, people skills, or essential skills) is the term used to encompass everything from interpersonal

*The $e$-Xtra logo stands for "electronic extra" and indicates that three supplementary figures are available online.

Accepted for publication 23 June 2016.

http://dx.doi.org/10.1094/PDIS-03-16-0354-FE

This article is in the public domain and not copyrightable. It may be freely reprinted with customary crediting of the source. The American Phytopathological Society, 2016 skills, personality traits, temperament, enthusiasm, and includes the ability to lead and manage (Schultz 2008). Soft skills are often separated into two categories, leadership and management, which share similarities but are not necessarily the same thing. For our purposes, we define management skills as the skills necessary to plan, coordinate, and support a team, department, or group by focusing on the necessary tasks to complete objectives. Management frequently applies to the supervision of employees and subordinates and the coordination and execution of existing plans, and implies that the people subject to management have incentives to participate in and comply with the management plan (Day 2000). There is a degree of overlap between the two categories, as many skills (e.g. communication) are critical for both types of skill sets.

We define effective scientific leadership as the ability to envision, facilitate, and enable the production of science, as well as manage the transfer and application of scientific knowledge from within their organization to the broader society, and to do so with integrity. Success in developing innovative science requires that lead scientists be able to attract, develop, and maintain a diversity of reputable scientists and support them in ways to allow them to be creative and motivated. To do so proficiently requires a diversity of skills such as communication, critical thinking, and management of people, project, and budgets. Equally important are skills like resilience, emotional intelligence, and conflict resolution, which are essential for facing challenges and obstacles along with entrepreneurship, visioning, and persuasion to encourage others to think more broadly and beyond the task at hand. In a 2011 survey, soft skills were ranked most important by employers and alumni, while discipline knowledge was ranked most important by faculty and students (Crawford et al. 2011).

\section{Where We Are}

In 2015, a 22-question survey developed by the authors. This survey was validated (questions were pretested and checked) by the American Phytopathological Society (APS) staff members and members of the APS Leadership Institute before it was distributed to the APS membership (Qualtrics 2016). The objective of the survey was to assess the types of leadership and management training members have obtained, where training occurred, how the training was perceived, and if additional training, professional development, and leadership skills were desired. The 579 APS members who responded to the survey reflected the general population of the membership, with education levels ranging from associate degree to Ph.D. with a large emphasis on scientists with M.S. and Ph.D. degrees (95\%). Fifty-seven percent of the participants identified themselves as working in academia, $21 \%$ as working in government, $13 \%$ as working in industry, and $9 \%$ as working in "other" occupations (consultants, diagnosticians, technical managers, lab managers, etc.). Survey participants came from 
all levels of academia (ranging from graduate students to former university presidents), all levels of government (ranging from technicians and research associates to national program staff), and all levels of industry (ranging from graduate students to executive directors). Survey participants provided selected comments (italicized).

Nearly all of the participants had supervisory experience as part of their position at some point in their career, and $82 \%$ of the participants were currently supervising others on a daily basis, indicating that supervision and management are definitely skills that are used in the career of the vast majority of scientists (Fig. 1). Supervision rates were higher among permanently employed scientists, but more than three-quarters of graduate students and postdoctoral researchers were also active in supervision of others $(76.5 \%)$.

Most people surveyed reported that they supervised between two and seven people. As might be expected, there was evidence of a "supervision pyramid" as a majority of the survey participants had supervised undergraduates, graduate students, and technical staff. Graduate students and postdocs had mostly supervised undergraduate students $(65.3 \%)$, followed by other graduate students $(31.6 \%)$, technical staff (21.4\%), and rarely other postdocs (3.1\%). Experience supervising students and postdocs was more common among permanently employed scientists, ranging from 42 to $80 \%$. Significantly fewer scientists had supervised people at the principal investigator (PI) level or within administrative staff, reflecting the smaller numbers of scientists that reach the chair/research leader level (Supplementary Fig. S1). A clear majority of scientists have managed others, even in the early stages of their training process. However, survey participants reported a lack of training and preparation to effectively supervise others.

"I only received training in science! Further training for all in these areas will make us better, more competent employees and scientists in the long run."

"Graduate school does not prepare you for the workplace. It prepares you to be a postdoc or a technician. If you have the right profile, age and are very lucky you may be singled out to be prepared for a faculty level position."

"As someone with an M.S. who suddenly finds themselves in charge of a lab with students and other employees to manage, I think management and leadership are very important topics that are often overlooked in our formal education."

"Any help with leadership and team building skills would be beneficial to a person starting out to be in a supervisory role."

\section{Percent of APS scientists who}

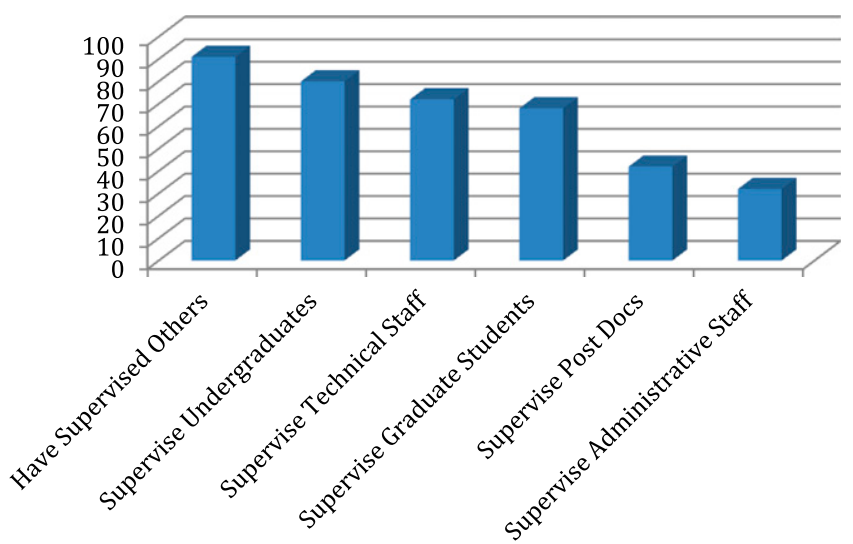

Fig. 1. Supervision roles for APS scientists, combined results for academic, government, and industry survey participants.
In addition to carrying out managerial activities, the majority of survey participants also reported serving in multiple leadership roles within their place of work (Fig. 2). Among permanent employees, service on committees and chairing of work related committees were more common. Graduate students and postdocs also participated on work related committees, although mostly as participants rather than as the chair of the committee. This may reflect a desire by many advisors and employers to expose scientists-in-training to the leadership process early.

The survey indicated that the vast majority of scientists will manage others over the course of their career, and a majority of scientists will serve in leadership roles either at work or in scientific societies. Survey participants actively participated in the leadership of scientific societies (Fig. 2 and Supplementary Fig. S2). Fifty-eight percent reported serving on one or more committees for a scientific society, and $41 \%$ had chaired a committee. Twenty-five percent of the participants had developed workshops and/or symposia for meetings, $23 \%$ had served in the elected or appointed leadership structure of a scientific society, and $15 \%$ had served as an elected or appointed leader within APS.

"My first leadership role was as Secretary/Treasurer of the Southern Division. This was the idea of my department head and was not something that I would have considered, but once involved I began to realize that I had some aptitude in leadership. Without that push from my department head, I don't know when I would have gotten involved. Now I see the importance of good leadership and wish I had gotten more involved earlier."

"My most valuable professional training came as a consequence of being an engaged member of APS."

Recognizing the Gap. The results of the APS survey suggest that traditional plant pathology training falls short in preparing participants to manage and lead other scientists. Even though $91 \%$ of respondents reported supervising (managing) someone else at some point in their career, just $30 \%$ of survey participants reported that their formal training had prepared them to manage others, and $36 \%$ of participants stated that their formal training had prepared them for leadership roles (Table 1). The number of survey participants reporting that their formal training had prepared them for management and leadership roles was slightly lower among scientists with permanent jobs (26 and 32\%, respectively). Fifty-eight percent of participants had received some form of professional development or leadership training, with the majority of those participants having received their training either from current employers, from APS, or had arranged and paid for training on their own (Fig. 3). Among participants who had not received training, the most common reasons for lack of training was either lack of access to training or lack of knowledge that training on these skills was even available (Fig. 3).

"As a graduate student I was not encouraged to develop any of these skills and was discouraged from doing anything that was not thesis related. I have had to learn these skills on my own."

\section{APS Scientist Leadership Activity (\%)}

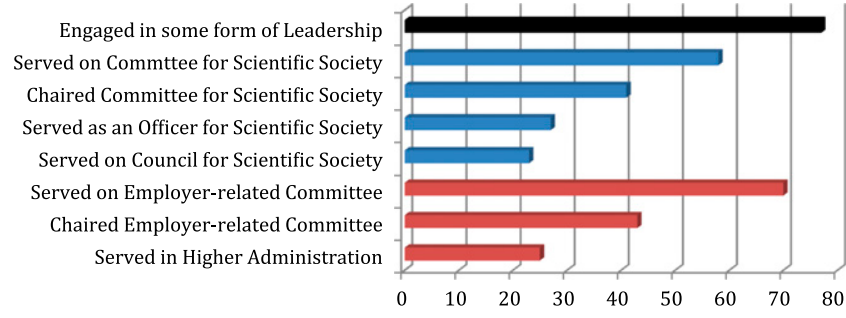

Fig. 2. Survey participant leadership roles within scientific societies (blue bars) and place of employment (red bars). 
"Scientific training (or at least what I got) was all about doing science and nothing else-no leadership, management, writing, or speaking training, even though those are the most important for success (provided your science is solid)."

This training deficit was not tied to employer resistance. Only $1 \%$ of participants said their employers were actively discouraging them from seeking soft skills training. Forty-nine percent of participants said that their employers took no position on encouraging or discouraging leadership and management skills training, $43 \%$ of participants reported their employers actively encouraged training, and $6 \%$ of participants said their employer required periodic training in leadership and/or management skills. This is comparable to a 2005 survey of postdoctoral scientists that found only $44 \%$ reported that their advisors encouraged them to obtain such education, $48 \%$ felt no pressure either way, and $8 \%$ were discouraged from pursuing such training (Davis 2005). Twenty-four percent of participants reported that their employers offered in-house leadership or management skills training frequently (at least yearly), $51 \%$ of participants indicated that their employers offered training occasionally, and $26 \%$ of participants stated their employers never offered training. The attitudes of employers toward employee training in leadership and management skills were not affected by whether the employee was permanent or not (data not shown).

\section{Training Topic Analysis}

A list of basic management and leadership skills was created and APS survey participants were asked to identify the topics and types of training they had received. (Table 2, Fig. 4). For every skill in the survey, scientists most commonly described their level of training as either "none" or "informal (from the observation of others)," suggesting that many critical skills were either being developed independently without formal training, or imparted from mentors who had received little or no training themselves. Most scientists received training in a limited number of areas $(86.9 \%$ of survey participants were trained in less than 10 of the 26 topics), while less than half had received training in more than three topics $(40.3 \%)$. Selfdirected studies, either via reading or Internet resources, were identified as a common means to learning new skills, suggesting that time and convenience may play a significant role in determining how scientists choose to advance their leadership and professional skill sets.

There were also differences in the levels of training survey participants had received in different topics (Table 2). Formal instructorled training was more frequently received in science and career track related topics. Many scientists had received some formal training in professional skills such as critical thinking, or improved written and oral communication skills. Survey participants had also frequently received training in skills that were fundamental to maintaining effective working environments, such as conflict resolution, people management skills, and team building. The least frequently trained skills were ones that are not usually associated with the practice of science, like entrepreneurship, resilience, visioning, and persuasion. The number of survey participants who had received any sort of formal training in these topics was even lower (Table 2).

Table 1. Survey responses from APS members about management and leadership training as part of their formal degree process

\begin{tabular}{lccc}
\hline & Yes & No & Not Sure \\
\hline $\begin{array}{l}\text { Has your training prepared you to manage } \\
\text { others? }\end{array}$ & $30 \%$ & $56 \%$ & $15 \%$ \\
$\begin{array}{l}\text { Has your training prepared you for } \\
\text { leadership roles? }\end{array}$ & $36 \%$ & $47 \%$ & $16 \%$ \\
$\begin{array}{l}\text { Have you received helpful professional } \\
\text { development or leadership training? }\end{array}$ & $58 \%$ & $34 \%$ & $8 \%$ \\
\hline
\end{tabular}

\begin{abstract}
"Most of my professional skills were learned from mentors for whom or with whom I worked. The farm business person ... taught me more about efficient management and critical thinking that one could ever find in any workshop."
\end{abstract}

\section{"Most of the topics listed above were not taught in graduate school. I had to learn the hard way."}

The prevalence of informal observation of others as a means of acquiring soft skills (Fig. 4) suggests that scientists primarily learn on the job from mentoring by advisors and colleagues. Previous findings by Ragins and Cotton (1999) identified informal mentoring as more beneficial to protégés than formal mentoring programs. This de facto "informal" mentoring was found to provide coaching and opportunities, in addition to role modeling, or providing friendship, with far greater benefits than formal mentoring programs (Ragins and Cotton 1999). While this informal type of learning can be a very effective way to derive skills, the quality of learning correlates directly to the quality of the person setting the example. As described above, the scientists in charge were selected for scientific productivity and not necessarily leadership and management skills regardless of setting. This reliance on informal observation to train our future scientists using untrained mentors carries significant risks, as the students propagate the "skills"—good or bad-that their mentors impart to them on a daily basis. Supplementing the observational acquisition of soft skills with professionally directed training provides scientists with more intentional learning (e.g., goal directed instruction like workshops or classes, as opposed to passive observation), which was identified as desirable by survey participants.

There were also significant differences in the levels of interest survey participants had in receiving training in different topics (Supplementary Fig. S3). Similar to the results obtained for "training received" category, interest in future training was higher in science and career track related topics, and survey respondents noted a preference for professional development and management skills over leadership skills: people management, project management, grant writing skills, and budget development and management ranked highest. Most scientists have experienced the frustration of seemingly simple activities, like running a meeting, resulting in failure. New scientists, postdocs, and graduate students recognized this and other failures, with a substantial number (32\% or more) expressing interest in obtaining people management skills. Only $8.5 \%$ of those surveyed were provided with any training in managing budgets in a formal setting. This number only rises to $26.4 \%$ receiving on-thejob budget management training. Not surprisingly, project management, budget development and management, and grant writing skills scored highest among workshops most desired by the APS membership.

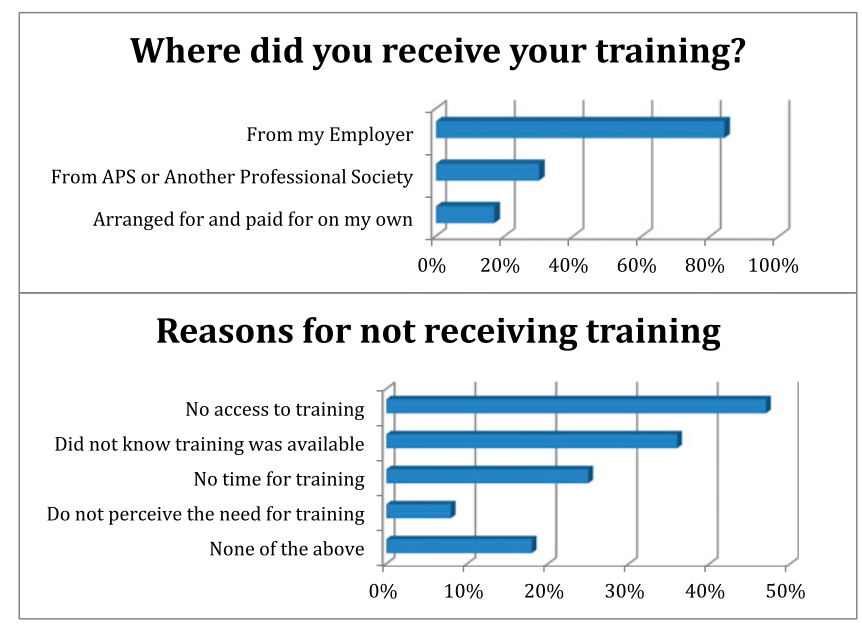

Fig. 3. Sources of leadership and management training and reasons for not receiving training among survey participants. 
In a 2015 study of business organizations, coaching, followed by communication, resiliency, critical thinking, collaboration, and data analysis were identified as the skills that were most critical to develop (Brandon Hall Group 2015). One surprising result of the APS survey was the lack of interest in specific topics considered fundamental to leadership, such as resilience (1\%) and self-awareness (2\%), both of which ranked at the bottom of desired topics that would benefit scientists most. While survey participants clearly recognized the need for leadership training (the vaguely worded cumulative category "leadership skills" ranked highly at 19\%), there was a clear disconnect when it came to assigning value to some critical leadership topics. This could be related to the difficulty of connecting these topics to what is popularly considered scientific skills, lack of understanding of the topic, or possibly to a general lack of available training resources for these topics. Regardless, this disconnect suggests that scientists may need help in recognizing areas where training would be beneficial to their leadership skills.

\section{Where Does This Leave Us?}

Starting a research lab, whether it is in academia, government, or industry, is very much like starting a business, complete with startup costs. The investments in these scientists are considerable; in 2003 the average startup cost for a new assistant professor in biology at a public research I institution was over $\$ 300,000$ (Ehrenberg

Table 2. Training received by APS survey participants sorted by topic and type of training. Numbers represent the percentages of total responses for each type of training within topics

\begin{tabular}{|c|c|c|c|c|c|c|c|c|}
\hline \multirow[b]{2}{*}{ Topic } & \multicolumn{8}{|c|}{ Type of training received (\% of participants) } \\
\hline & None & $\begin{array}{c}\text { Informal } \\
\text { observation }\end{array}$ & $\begin{array}{l}\text { Self-directed } \\
\text { reading }\end{array}$ & $\begin{array}{l}\text { Self-directed } \\
\text { internet }\end{array}$ & $\begin{array}{l}1 \text { to } 4 \text { hour } \\
\text { seminar }\end{array}$ & $\begin{array}{l}1 \text { to } 2 \text { day } \\
\text { workshop }\end{array}$ & $\begin{array}{l}3 \text { to } 5 \text { day } \\
\text { workshop }\end{array}$ & $\begin{array}{c}\text { Formal } \\
\text { course }\end{array}$ \\
\hline Creative thinking and innovation & 23.6 & 24.5 & 22.0 & 9.8 & 9.2 & 6.3 & 3.3 & 1.3 \\
\hline Emotional intelligence & 33.7 & 21.7 & 20.7 & 6.2 & 7.9 & 5.8 & 2.1 & 1.9 \\
\hline Leadership skills & 16.6 & 23.0 & 14.3 & 9.0 & 9.2 & 12.8 & 8.5 & 6.6 \\
\hline Persuasion & 42.8 & 27.4 & 12.6 & 8.0 & 3.4 & 3.0 & 1.2 & 1.6 \\
\hline Strategic thinking & 26.6 & 26.0 & 18.8 & 9.1 & 7.7 & 5.3 & 4.4 & 2.1 \\
\hline Visioning & 40.9 & 24.0 & 13.1 & 6.3 & 6.3 & 5.2 & 2.3 & 1.9 \\
\hline Conflict resolution & 22.2 & 21.3 & 11.0 & 7.9 & 19.1 & 12.0 & 3.4 & 3.1 \\
\hline Motivating others & 22.7 & 29.0 & 18.1 & 10.0 & 7.3 & 7.3 & 3.1 & 2.5 \\
\hline Resilience & 46.6 & 26.8 & 14.8 & 5.8 & 1.9 & 2.9 & 0.4 & 0.8 \\
\hline Self-awareness & 35.0 & 25.5 & 17.1 & 7.8 & 4.5 & 4.9 & 2.5 & 2.7 \\
\hline Budgeting & 30.2 & 33.3 & 14.2 & 7.3 & 6.3 & 5.4 & 1.1 & 2.2 \\
\hline Networking & 21.3 & 34.2 & 17.5 & 10.0 & 7.2 & 6.1 & 2.4 & 1.3 \\
\hline Entrepreneurship & 55.1 & 15.3 & 12.4 & 4.1 & 6.5 & 2.7 & 1.2 & 2.7 \\
\hline Mentoring & 21.6 & 31.6 & 17.0 & 8.8 & 8.6 & 6.3 & 3.6 & 2.5 \\
\hline People management & 20.3 & 27.9 & 16.1 & 8.0 & 9.9 & 9.5 & 4.6 & 3.7 \\
\hline Project management & 25.7 & 28.5 & 18.1 & 7.9 & 7.6 & 6.3 & 3.6 & 2.3 \\
\hline Team building & 22.2 & 24.2 & 14.9 & 6.8 & 12.2 & 9.7 & 5.9 & 4.1 \\
\hline Oral communication & 12.2 & 24.2 & 17.6 & 10.2 & 15.0 & 8.7 & 2.1 & 10.0 \\
\hline Written communication & 13.7 & 25.3 & 21.8 & 11.1 & 10.1 & 7.7 & 1.7 & 8.6 \\
\hline Career prep & 28.0 & 27.3 & 19.3 & 11.3 & 7.1 & 3.0 & 1.1 & 2.9 \\
\hline Critical thinking & 20.3 & 24.9 & 27.7 & 8.1 & 7.2 & 5.4 & 2.8 & 3.6 \\
\hline CV preparation & 19.4 & 27.6 & 22.9 & 15.3 & 10.3 & 2.5 & 1.0 & 1.0 \\
\hline Grant writing & 16.9 & 23.4 & 18.7 & 8.9 & 14.8 & 10.2 & 3.8 & 3.3 \\
\hline Interviewing skills & 28.9 & 24.3 & 18.4 & 12.7 & 9.3 & 3.4 & 1.3 & 1.7 \\
\hline Professionalism & 23.4 & 31.7 & 18.3 & 9.3 & 8.5 & 3.5 & 2.0 & 3.3 \\
\hline Work/life balance & 32.3 & 23.8 & 15.8 & 9.1 & 9.9 & 5.3 & 1.5 & 2.3 \\
\hline
\end{tabular}

\section{Sources of soft skills training}

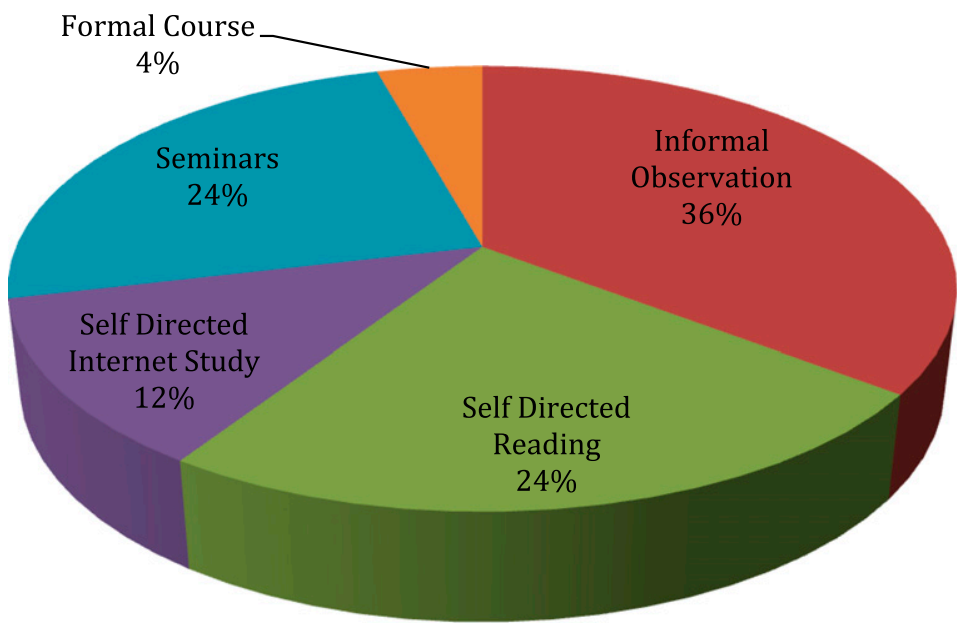

Fig. 4. Sources of soft skills training for APS survey participants. 
et al. 2003), a cost that is surely rising, ranging up to $\$ 1.4$ million (Simpson 2005).

"Negotiating a job offer might be a good skill."

"The business of being a scientist (i.e. budget planning and project management) should be incorporated into graduate school curricula ... While most academic scientists may only need these skills early in their career, corporate scientists may need to rely on these skills often during their careers."

As a new lab leader, the scientist is quickly confronted with multiple demands in order to establish a laboratory_planning a research program, developing collaborations, hiring staff and "interns" (students), obtaining grant funding, and publishing results in journals. Scientists are trained to rely on logic and data. People (including scientists), however, operate on emotion and habit, often resulting in conflict when data and objectivity collide with different personality types and emotions. Respondents reported that training in emotional intelligence, conflict resolution, and management was helpful in their day-to-day management and leadership; however, little research has been performed in any field regarding empirical assessment of these reports.

"Some of the most important training I have taken and provided my staff was the personality testing and how different personalities interact - it was very revealing to staff."

"The most amazing leadership workshop ... utilized the MyersBriggs MBTI personality test and involved group exercises that helped everyone understand how we all have different approaches to work and personal interactions."

"I participated in the Effective Team Leadership workshop held at the 2013 APS annual meeting. I found this workshop to be extremely valuable and use the information package I received regularly. This workshop has led me to pursue a DISC workshop at my workplace, specifically for my team."

Many of the survey participants' comments focused on new scientists in both faculty and industry positions. However, leadership and management skills are important to all scientists as they evolve, and are necessary for long-term success (Bancino and Zevalkink 2007).

\section{"Early in my life I became Dean ... and suffered a lot to man- age that giant institution. I feel that I could have suffered less and be more efficient if I had the right training. For six years I had to battle against inefficiency to reach my objectives. I succeeded at the end but at a high cost because of complete lack of a formal leadership training." \\ "Every job is different. My work with government differs a great deal from someone that is working in industry or for ac- ademia. Certain skills will be applicable only within those set- tings. However, there are universal skills that every leader or potential leader should have..."}

The bottom line is that scientists (and the managers and leaders who work with them) recognize that soft skills are increasingly important in an era of big-budget, multidisciplinary grants, and that developing these skills improves their performance. Money that once went to individual practitioners has shifted, and is now awarded to multidisciplinary teams working on problems of increasing complexity, a fact that was recognized over 50 years ago (Pelz and Andrews 1966). As these areas of inquiry become more complex, so do the multidisciplinary approaches used to address them. This increased requirement for effective interactions drives the need for the soft skills necessary to complement and fully utilize the technical skills that plant pathologists are trained in. Any failure to develop these soft skills will impact current and future scientific endeavors.

\section{The Evolution of Leadership}

Soft skills are critical to any professional career track, including plant pathology, as the natural trajectory of science careers often leads from working on individual projects or individual projects as a member of a team as graduate students or as postdocs, to supervising, to leading teams of scientists working toward common objectives and responsibilities. Startup costs are one readily quantifiable measure of expense during this process. Less quantifiable is the human cost in achieving this level of success and maintaining it (Davis 2005). With an average age of 38, not all new scientists or new assistant professors should necessarily be considered "young" (Mathews 2014). Regardless of age, all people have personal obligations and potentially family obligations, in addition to the added pressures of tenure clocks and biological clocks - all of which create an enormous amount of stress.

"It's a bit overwhelming starting a new job and having the added demand of figuring out how to be an effective manager. Some things you can only truly learn by experience but it would have been nice to have had some training prior to becoming a manager."

"Work-life balance could particularly help graduate students and early career professionals as they try to decipher how much is "enough" and wade through the stress of trying to have a life, while at the same time performing well in front of their superiors."

\section{"... I would recommend that most of us would benefit from programs on work-life balance.”}

The very focus on scientific training that made the new scientist successful in research may have paradoxically prevented the scientist from developing good management skills, and good work-life balance. The transition to any permanent job comes with a large learning curve, and the first years in any new position are very taxing on their time, resulting in additional stress. Anything that can reduce the time expenditures associated with a new position, like training in leadership, management, and professional development, becomes advantageous.

This painful, inefficient, and costly process of developing a scientific career doesn't end with obtaining a permanent position, or even tenure in academic positions. Career development is a process, not a destination. Even people who have "successfully" navigated the process and arrived at their desired location (whether in industry, government, or academia) often report feeling damaged and question the price of success (Mathews 2014). In a 2014 COACHE survey, tenured associate professors generally rate their satisfaction and experiences lower than do assistant and full professors (Mathews 2014). The midcareer and later development process for scientists is often lacking. As scientists mature, they often find their roles expanding, requiring leadership in teaching, public policy, entrepreneurship, extension, and outreach. Suddenly, the once successful scientist is blindsided not only by the magnitude of the expanded mission, but also by their loss of identity when they are "promoted" into management, without the appropriate tools to become successful in their new roles.

"My observations over the years have shown that good scientists are not necessarily good managers-the two positions require very different skills. Of the managers I have known, myself included, most were not prepared to handle the diversity of tasks required to manage people. We are often just 
moved into positions without any training or guidance and expected to be able to motivate, encourage, and resolve conflicts or handle different personalities."

\section{Communication}

One of the most important skills that respondents focused on was communication, about science and between scientists (Crawford et al. 2011). Scientists, like most people, talk but often fail to communicate. Communicating effectively is of enormous importance to both managing and leading effectively, and underpins other leadership skills such as persuasion, conflict management, team building, and visioning. Effective communication in plant pathology (and all science for that matter) requires that difficult concepts and distinct language differences between disciplines (e.g., bioinformatics, field studies, bench research) be clarified in order for effective communication to occur. Superimposed upon these difficulties is the fact that for many scientists, English is not the primary language, adding to the challenges of communication.

"Communication, both written and oral. This is so integral to one's professional success, it's not even funny. You absolutely must be able to tell your "story" in a manner that your target audience can understand. The flipside of that is that you must be able to listen."

While oral and written communication skills were easily recognized and highly valued by survey participants, the value of more implicit communication skills like social awareness, assertiveness, and intercultural awareness is less recognized in science. The most effective presentation of information can easily be wasted if the presenter lacks the skills to recognize the audience's background, perceptions, and cultural influences.

"Interpersonal skills are key to succeeding in the scientific arena, and this is commonly lacking in scientists at all organizations that I have worked at."

"I took an extensive course on understanding/working with behavioral styles. It opened my eyes to why friction can develop between colleagues even in the absence of true conflict. It also provided tools on how to deal with people of different styles."

Successful communication requires having the interpersonal skills to recognize differences in not only style, but in experiences and culture. Training to improve interpersonal skills and communication are important means of not only avoiding misunderstandings, but also have the potential to improve upon how information is shared and how science develops by being more inclusive.
These skills will become increasingly important as the demographics shift to younger workers, and the number of women and minorities increase and diversify the workforce. Multiple lines of evidence have demonstrated that younger Americans often begin their education with interest in science but leave to pursue more appealing opportunities. This trend appears particularly acute among women and under-represented minorities (Goulden et al. 2011 and references cited therein). The good news for APS is that our number of young people and women in science has been increasing in the last six years, although the majority of the organization is over the age of 45 (Table 3). Unfortunately, ethnic diversity in APS remains static, despite the fact that organizational diversity is increasingly recognized as an asset in industry, government, and academia. APS is an international society, and our continued success depends upon the ability to include everyone.

"I was an international student in the U.S.A. and currently

I am back in my citizenship country (a poor/developing one). Therefore, my case may be different from the average. I feel very unprepared to follow faculty tenure track career."

\section{Addressing the Gap}

One obvious and available solution to the lack of leadership and management training is taking advantage of the university setting. Academic institutions have a good appreciation of the necessity and value of leadership and management training, and many universities have developed programs or institutes specifically for management and leadership skills. Every institution that supports the plant pathology or plant science graduate programs listed on the APS directory (http://www.apsnet.org/members/directories/Pages/PPPrograms.aspx) has leadership and/or management skills training available through credit classes, workshops, and/or symposia. Some plant pathology programs have started to incorporate professional development, management, and leadership training as requirements or electives within the degree process. This process needs to be continued and expanded.

"As a Ph.D., most of the jobs that I am qualified for have some management component. I spend 1/2 my time at work managing others and budgeting. I feel that I learned how to think critically and overcome obstacles in graduate school but was never taught how to manage and lead others ... Graduate school seems like a logical place to receive this training."

"In general, Ifeel the Ph.D. preparation is very far away from the reality of faculty/academia work. Thus, I really think the real change should address not a few hours seminar/workshop, but it should be complete courses included in Masters' and Ph.D. programs to address these needs."

Table 3. APS demographic comparisons from 2010 to 2015

\begin{tabular}{|c|c|c|c|c|c|c|}
\hline ETHNIC & 2010 & 2011 & 2012 & 2013 & 2014 & 2015 \\
\hline American Indian/Alaskan native & $0.22 \%$ & $0.23 \%$ & $0.12 \%$ & $0.13 \%$ & $0.06 \%$ & $0.00 \%$ \\
\hline Asian or Pacific islander & $14.59 \%$ & $15.21 \%$ & $14.68 \%$ & $14.31 \%$ & $14.04 \%$ & $13.32 \%$ \\
\hline Black, not of Hispanic origin & $1.48 \%$ & $1.65 \%$ & $1.62 \%$ & $1.26 \%$ & $1.55 \%$ & $1.62 \%$ \\
\hline Hispanic & $5.27 \%$ & $5.01 \%$ & $5.09 \%$ & $4.98 \%$ & $4.98 \%$ & $4.53 \%$ \\
\hline White, not of Hispanic origin & $78.33 \%$ & $77.83 \%$ & $78.43 \%$ & $79.32 \%$ & $79.37 \%$ & $74.45 \%$ \\
\hline GENDER & 2010 & 2011 & 2012 & 2013 & 2014 & 2015 \\
\hline Male & $70 \%$ & $68 \%$ & $69 \%$ & $73 \%$ & $70 \%$ & $68 \%$ \\
\hline Female & $27 \%$ & $27 \%$ & $28 \%$ & $27 \%$ & $30 \%$ & $32 \%$ \\
\hline AGE & & 2011 & & 2013 & & 2015 \\
\hline$<25$ & & $3.13 \%$ & & $4.93 \%$ & & $4.73 \%$ \\
\hline $25-34$ & & $13.03 \%$ & & $13.68 \%$ & & $14.53 \%$ \\
\hline $35-44$ & & $16.79 \%$ & & $17.04 \%$ & & $17.96 \%$ \\
\hline $45-54$ & & $25.54 \%$ & & $21.40 \%$ & & $19.43 \%$ \\
\hline $55-64$ & & $22.21 \%$ & & $22.93 \%$ & & $22.62 \%$ \\
\hline$>65$ & & $19.31 \%$ & & $20.02 \%$ & & $20.73 \%$ \\
\hline
\end{tabular}


Incorporating professional development training into graduate programs faces many obstacles, including limited funding opportunities and time constraints associated with graduate training. With the minimal number of coursework credit hours required for graduation ranging from 9 to 30 for a Ph.D., there is little incentive for advisors to encourage students to take courses in leadership, management, or professional development, despite the proportion of students pursuing the "nontraditional" career path (Cyranoski et al. 2011). Although student-training grants through USDA and NSF exist, most graduate programs in the sciences focus on the generation and dissemination of research. Graduate student professional development is not considered an important output, let alone an outcome; however, recommendations have been made for reviewers to "broaden their conception of 'successful' training outcomes" and to recognize nontraditional outcomes that meet important national priorities and needs (NRC 2011). Faculty, students, alumni, and employers all ranked guided, active, intentional learning as more effective than self-directed and informal learning experience (Crawford et al. 2011).

A common concern is that encouraging students' professional development will detract from research time in the lab, and reduce scientific outputs and quality of research. Currently, graduate students and postdoctoral students comprise a considerable portion of the research workforce (NRC 2011). Frequently, both tuition and stipends to support trainees are funded by PIs' research grants, creating an obvious conflict of interest for the PI who is evaluated on research outputs (Benderly 2010). In order for this situation to improve, plant pathology departments and funding agencies should consider taking steps to ensure that scientists-in-training are being broadly prepared for their future careers, and not just trained in current research topics, data management issues, and ethics, as is currently required by many funding agencies (NRC 2011). This isn't to suggest that the scientific training is not important. Rather, the challenge becomes incorporating additional important soft skills content while maintaining a proper balance with scientific training. The wealth and diversity of training options allow for strategic integration of soft skills without negative effects on scientific training. This can be done by altering journal clubs, taking full advantage of extension opportunities, and utilizing on-campus resources effectively.

For those people that have established careers, there are options for plant pathologists to obtain leadership and management training. Commercially available leadership and management training is a staple of the business community, and as such many commercial providers have a business-centric approach to training topics and content. Many agriculture industries already take advantage of these resources, and some companies have developed their own internal leadership training option. There are additional training options that are specific to the needs of scientists in academia and government positions.

Scientific societies have also begun to incorporate or increase professional skills training into their meeting programs, either on the local or national level. Symposia and workshops about grant writing, job opportunities, and professional skills are becoming more frequent additions to meeting programs, and nearly all scientific societies have committees focused on the needs of early career professionals. In addition, most scientific societies have initiated some level of online career resources, although most frequently this takes the form of a job listing site. APS has a good history of recognizing the importance of incorporating content outside of the traditional scientific content into the annual meeting structure. For example, the 2012 APS annual meeting plenary session focused entirely on the importance of communicating plant pathology to nonscientists. In addition, APS has developed the Career Advancement and Development Resources and Education (CADRE) website and committee dedicated to the generation and maintenance of an online career development resource (http://www.apsnet.org/careers/CADRE/Pages/default.aspx, for APS members only). However, the clear majority of university and scientific society skills training takes the form of professional training, focusing on the skills necessary to get a job and procure funding, excluding many of the interpersonal skills, communication skills, and leadership skills necessary to thrive once the new scientists take on the expanded roles associated with permanent positions. In 2009, APS initiated the Leadership Institute, which organizes leadership training for APS members at the annual meeting. Since its inception, the Leadership Institute has trained 139 members, including all career stages and career tracks, on topics such as conflict resolution, team building, and self-awareness. Fifty-six percent of LI training alumni went on to take additional leadership roles within the society (compared with $30 \%$ of scientists in the general membership that take leadership roles within the society).

Online educational resources represent a rapidly growing sector of training options. Many plant pathology programs already take advantage of the ease of online communication to offer multi-institution plant pathology courses. Self-directed online studies are highly popular as potential students can control the timing to fit training in around their already busy schedules. Survey participant comments reflected these views:

"I would do a lot of these trainings via my society if they were online and user controlled-like a click-through educational module. Meetings are too long already and I cannot be gone from work to do these. "

"There seems to be a glut of CV building, career prep, and interviewing skills information out there already and APS members would be better served with making those tutorials available online or informally."

Online leadership training would be a very viable avenue for augmenting the typical scientific graduate school regime. According to Training Magazine (1999), leadership skills training has grown into a $\$ 12$ billion industry, so ample opportunity exists in a diversity of price ranges. The ability of multiple institutions or even multiple scientific societies to share resources to achieve a common training curriculum is very achievable, provided that the community is willing to make the upfront time investment necessary to develop and disseminate quality training resources.

It is important to recognize that leadership training and development, just like a scientific career, is strategic and long-term. In a 2015 study, one-third (36\%) of organizations surveyed reported that their leadership development practices were still below average or poor (Brandon Hall Group 2015). One course alone cannot ensure the breadth of training necessary for plant pathologists to be prepared for the constant change that will occur not only in their area of scientific or technical expertise but in their lives and careers, too. Improving leadership, management, and professional development skills is a continuous process, not the result of occasional events.

\section{Conclusions}

There is no correlation between doing science well and leading groups of people (with varying skill levels) doing research. The results from this survey demonstrate that most scientists who lead and manage other people (including other scientists) have little or no training in leading and managing people, or received informal training by watching others, as noted by Ragins and Cotton (1999).

\section{"I was fortunate to have an excellent graduate advisor and a very supportive graduate department. I think I probably learned more by watching and interacting with these faculty members regularly over the course of my graduate studies than I could learn in a seminar or workshop."}

Plant pathology is influenced by societal, institutional, environmental, and technological changes (Loper et al. 2005). In this survey, we sought to understand changes and assess opinions regarding leadership training and leadership needs of plant pathologists. Dr. Karen Plaut, Associate Dean of Agriculture at Purdue University stated, "While this survey was conducted with the plant pathology community, the results are applicable to most of the scientific community. 
We continue to train people in their scientific discipline without paying attention to soft skills needed in most careers. This survey points out the weaknesses that are evident in our graduate and young scientist training. We need to correct this now." This paper is titled "Mining the Gap" because the very act of mining suggests you can extract something valuable from a hole or deficit, or in this case, the gap between leadership needs and leadership training. Within this survey, it was broadly recognized that as a profession and as a professional society, we need to best position the discipline to meet future societal needs and scientific opportunities. To do so successfully, it was also clearly recognized that scientists require more than scientific rigor and technological expertise. After investments of hundreds of thousands (if not millions) of dollars per scientist, we need to be more conscientious as we train this next generation of scientists, and provide them the opportunities to learn beyond their technical expertise. Their "people proficiency" and soft skill sets need to be developed along with their scientific training. We simply cannot afford, in human costs, in time, and in dollars, anything less.

\section{Acknowledgments}

The authors would like to acknowledge Drs. Karen Plaut, Stephen Goodwin, and Kevin Gibson, Purdue University; Erika Saalau-Rojas, University of Massachusetts Extension Service; and Eric Tedford, Syngenta AG; for their critical review of the manuscript. The authors would especially like to acknowledge the late Dr. Andrew Leadbeater (Syngenta AG), for his review, for all his contributions and leadership within APS, and most of all, his friendship to so many. The USDA is an equal opportunity provider and employer.

\section{Literature Cited}

Austin, A. E. 2002. Preparing the next generation of faculty: Graduate school as socialization to the academic career. J. Higher Educ. 73:94-122.

Bancino, R., and Zevalkink, C. 2007. Soft skills: The new curriculum for hard-core technical professionals.Techn. Connecting Educ. Careers 82:20-22.

Benderly, B. L. 2010. The real science gap. Miller-McCune, 14 June 2010. Available online from: https://psmag.com/the-real-science-gap-f00edae57ba1\#. 6khzlkrtb.

Brandon Hall Group. 2015. 2015 State of Leadership Development Study: Top Findings. Available online from: http://www.brandonhall.com/HCMA/assets/ bhg_rs_2015_leadership_study_051515_final.pdf
Crawford, P., Lang, S., Fink, W., Dalton, R., and Fielitz, L. 2011. Comparative analysis of soft skills: What is important for new graduates? Available online from: https://ag.purdue.edu/oap/career/Documents/2012\%20Soft $\% 20$ Skills\% 20Survey\%202011\%20Crawford\%20Lang\%20Fink\%20Dalton\%20Fielitz.pdf

Cyranoski, D., Gilbert, N., Ledford, H., Nayar, A., and Yahia, M. 2011. The PhD factory. Nature 472:276-279.

Davis, G. 2005. Doctors without orders. Am. Sci. 93, Suppl. Available online from: http://c.ymcdn.com/sites/www.actscience.org/resource/resmgr/docs/doctors without_orders.pdf.

Day, D. 2000. Leadership development: A review in context. Leadersh. Q. 11: 581-613.

The Economist. 2010. The disposable academic. 16 December 2010. Available online from: http://www.economist.com/node/17723223?story_id=17723223

Ehrenberg, R. G., Rizzo, M. J., and Condie, S. C. 2003. Start-up costs in American research universities. Available online from: https://www.ilr.cornell.edu/sites/ ilr.cornell.edu/files/WP33.pdf

Gadoury, D. M., Andrews, J., Baumgartner, K., Burr, T. J., Kennelly, M. M., Lichens-Park, A., MacDonald, J., Savary, S., Scherm, H., Tally, A., and Wang, G.-L. 2009. Disciplinary, institutional, funding and demographic trends in plant pathology: What does the future hold for the profession? Plant Dis. 93:1228-1237.

Goulden, M., Mason, M. A., and Frasch, K. 2011. Keeping women in the science pipeline. Ann. Am. Acad. Pol. Soc. Sci. 638:141-162.

Loper, J., Vidaver, A., Blanger, R., Bergstrom, G., Frank, J., Gabriel, C., Kamoun, S., Leach, J., Lindow, S., MacDonald, J., Sherwood, J., and Wimer, M. 2005. Vision of Plant Pathology in the 21st Century. Available online from: http://www.apsnet. org/about/visionoverview/Documents/21stCenturyVisionofPlantPathology.pdf

Mathews, K. 2014. Perspectives on Midcareer Faculty and Advice for Supporting Them. Available online from: http://scholar.harvard.edu/files/kmathews/files/ coache mathews_midcareerfaculty_20140721.pdf

NRC. 2010. A Data-Based Assessment of Research-Doctorate Programs in the United States. National Academies Press, Washington, DC.

NRC. 2011. Research Training in the Biomedical, Behavioral, and Clinical Research Sciences. National Academies Press, Washington, DC.

Pelz, D. C., and Andrews, F. M. 1966. Scientists in Organizations. Wiley, New York.

Qualtrics. 2016. Validation. Accessed 18 February 2016 from: https://support qualtrics.com/survey-platform/edit-survey/editing-questions/validation.

Ragins, B. R., and Cotton, J. L. 1999. Mentor functions and outcomes: A comparison of men and women in formal and informal mentoring relationships. J. Appl. Psychol. 84:529-550.

Schulz, B. 2008. The importance of soft skills: Education beyond academic knowledge. Nawa J. Commun. 2:146-154

Simpson, R. S., Jr. 2005. Academic Tenure-Track Offer Letters. Burroughs Wellcome Fund. Available online from: http://www.bwfund.org/career-tools/ academic-tenure-track-offer-letters

Training Magazine. 1999. Industry Report 1999 - An Overview of EmployerSponsored Training in the United States. International Data Corporation, Framingham, MA.
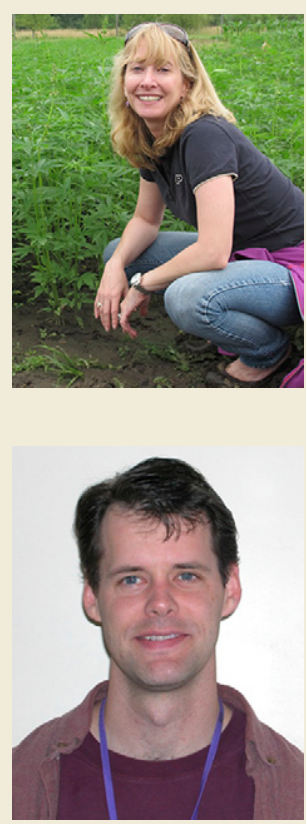

\section{Janna Beckerman}

Janna Beckerman is a professor and extension plant pathologist at Purdue University. Her research focuses on disease management of specialty crops, which informs both her extension and teaching responsibilities. She served as a member of the Leadership Institute since 2009 and was chair from 2012 to 2016. At Purdue University, she is the current faculty chair of the undergraduate Leadership Development Certification Program.

\section{William Schneider}

Dr. Schneider is a research plant pathologist for the USDA Agricultural Research Service Foreign Disease/Weed Science Research Unit in Fort Detrick, MD. His research focuses on diagnostics, biology, and evolution of vectored plant viruses and bacteria. He served as a member of the APS Leadership Institute from 2009 to 2015, co-chairing the committee in 2013. Currently he is active with the APS Professional Development forum. 